\title{
Developing Sport Environment Based on Motives of Different Ethnics
}

\author{
Vincent A. Parnabas ${ }^{1, *}$, Julinamary Parnabas ${ }^{2}$ \\ ${ }^{1}$ Faculty of Sport Science and Recreation, Universiti Teknologi MARA (UiTM), Shah Alam, 40450 Selangor, Malaysia \\ ${ }^{2}$ Institut Pendidikan Guru, Kampus Darulaman, Jitra, Kedah, Malaysia \\ *Corresponding Author: vincent@salam.uitm.edu.my
}

Copyright (C) 2014 Horizon Research Publishing All rights reserved.

\begin{abstract}
People from different cultural background show different motives for taking part in sports. Since lack of research in this area, there is still uncertainty on motives of different cultural groups in Malaysia. Malaysia consists of many ethnic groups with different cultural backgrounds, namely Malays, Chinese and Indians, maintain separate cultural identities. Knowing motives of different ethnics for participating in sports will help sports psychologists and sport industries to develop an appropriate sports environment for that ethnics. The present research will evaluate the motives that encourage different background ethnics to participate in sports, in order to develop sport environment according to each ethnic needs. The sample consisted of 231 athletes, with Malay ethnic athletes $(\mathrm{N}=101)$, Chinese ethnic athletes $(\mathrm{N}=73)$ and Indian ethnic athletes $(\mathrm{N}=57)$. A 30-item questionnaire called "Motives of Taking Part in Sport" was used. Six factors were derived from the questionnaire. They are socialization, high status career, green space area, music, body shape and challenges. The result showed that Malay ethnic group taking part in sport for green space environment, Chinese for body shape, while Indians for socialization. The findings of this study will be beneficial to government officials, private sectors, sports psychologists and sport industries in Malaysia in conducting sports centers, products or services to encourage different ethnics in Malaysia to take part in sports.
\end{abstract}

Keywords Motives, Sport Environment, Ethnic

\section{Introduction}

Motives can be defined as the intentions that cause a person to move, act, or to behave in a certain way (Brehm, 2004). There are many motives for participating in sports (Wann, 1997). Past studies, showed that the major motives athletes have for their spots participation are joy, for arousal, thrills and excitement, achievement, fitness, energy release, skill development, friendship, fun, and to become physically fit, healthy lifestyle (Bennett, Mousley, Kitchin, \&
Ali-Choudhury, 2007; Devine \& Lepisto, 2005; Gill, Gross \& Huddleston, 1983; White \& Duda, 1994).

A variety of cultural comparative studies have been conducted in the field of sports psychology. People from different cultural background showed different motives for taking part in sports. Some progress has been made in addressing this problem in developed countries, especially comparing among blacks and whites but a similar research is yet to be conducted in Malaysia. Since lack of research in this area, there is still uncertain on motives of different cultural groups in Malaysia in participating in sports. Malaysia consists of many ethnic groups with different cultural background, namely Malays, Chinese, Indians and other minority races, maintained separate cultural identities (Kahn, 1998).

In Malaysia, Malay is the largest ethnic, comprised $50.4 \%$, followed by Chinese, $23.7 \%$, indigenous $11 \%$, Indians $7.1 \%$, and others $7.8 \%$ (East Malaysia, especially Iban and Kadazan) (Malaysia Demographics Profile, 2012). The religions in Malaysia are Muslim (or Islam - official) covered $60.4 \%$, followed by Buddhist $19.2 \%$, Christian 9.1\%, Hindu $6.3 \%$, Confucianism, Taoism, other traditional Chinese religions $2.6 \%$, other or unknown $1.5 \%$, none $0.8 \%$. Almost all the Malay ethnic are Muslims. The languages (which resemble ethnic background) are Bahasa Malaysia (official), English, Chinese (Cantonese, Mandarin, Hokkien, Hakka, Hainan, Foochow), Tamil, Telugu, Malayalam, Panjabi, Thai (Malaysia Demographics Profile, 2012). Furthermore, in East Malaysia, exist several indigenous languages; widely spoken are Iban and Kadazan ethnic. Sometimes it's hard to believe that we remain in the same country, but their way of living differs dramatically from the other.

There are many reasons why Malaysian athletes begin to participate in sports. For example, in a research done by University Putra Malaysia, with200 student-athletes, it was found that the six important motives, out of 30 motives, given by students for sports participation were achievement, body shape, physical fitness, teamwork, learning new skills and for challenges (Sim Poh Chuen. 1994). The same study also found that friendship and strong desire to become 
popular are the lowest motive for sport participation among these student-athletes.

A number of researches have been conducted on motives for sports participation in developed countries (Wann, 1997), but, there is a lack of such research in developing countries, including Malaysia especially on different ethnics. Furthermore, research comparing different ethnic athletes directly are very limited. Comparing motives of different races on taking part in sportscan bring a lot of new knowledge for cultural studies and can design sport industry according to the preference of each ethnic. There is a need to plan and attract people to consume sports product or center, but this will depend on their sports participation motives. Understanding the motives of those who are already involved in sports can be used as the guide line to design sport centers. Lindner and Kerr (2001) argued that the motivation to participate in a sport was both complex and multifaceted. Different motives could determine participation decisions to design the sport centers and environment.

Knowing motives of different ethnics for participating in sports will help sports psychologists and sport industries to develop an appropriate sports environment, center or programme for that ethnics. In addition, identifying the range of motives given by different ethnic participants will help sports psychologists provide adequate and variety of sports enviroment, centers, programmes or services to maintain interest among those ethnics. This is because understandings of why particular ethnic choose to take part in sports while others do not, could be of great practical value.

\section{Aim of the Study}

The present research evaluated the motives that encouraged different background ethnics to participate in sports, in order to develop sports environment according to each ethnic's needs. Three major ethics in Malaysia that took part in this study; are Malays, Chinese and Indians. Motives for taking part in sports include the following motives: socialization, high status career, green space area, music, body shape and challenges. Malaysians have a unique culture made up of customs, religion and belief that are different from each other's cultural groups. Thus, there is a need for research to be carried out on the motives of different ethnic groups of Malaysians for taking part in sports in order to develop sports environment according to their motives and needs.

\section{Method}

The sample consisted of 231 athletes, with Malay ethnic athletes $(\mathrm{N}=101)$, Chinese ethnic athletes $(\mathrm{N}=73)$ and Indian ethnic athletes $(\mathrm{N}=57)$. The sample was chosen from the universities'sports competitions, athletes who took part in Malaysian Inter-University Sports Competition. Participants' were identified according to their racial group as 'Malay', Chinese' or 'Indians' in the demographic questionnaire. A 30-item questionnaire called "Motives of Taking Part in Sports" was used. Athletes will indicate their responses to questionnaire on a Likert-typed scale ranging from strongly agree (5) and strongly disagree (1). Six factors were derived from the questionnaire. They are socialization, high status career, green space area, music, body shape and challenges.

\section{Result}

\subsection{Profile of the Respondents}

Frequency, Percentage, mean and standard deviation are presented in Table 1, which shows the overall results of the respondents' profile. The profile of the respondents described the ethnics, gender and age. There are 112 male and 119 female athletes participated in this study.

Table 1. Profile of the respondents

\begin{tabular}{|c|c|c|c|c|}
\hline Variables & Frequency & Percentage & Mean & SD \\
\hline Ethnics & & & & \\
Malay & 101 & 43.72 & & \\
Chinese & 73 & 31.6 & & \\
Indian & 57 & 24.68 & & \\
\hline Gender & & & & \\
Male & 112 & 48.48 & & \\
Female & 119 & 51.52 & & \\
\hline Age & & & 2.17 & 2.01 \\
Male & & & 21.77 & 1.91 \\
Female & & & & \\
Overall & & & & \\
\hline
\end{tabular}

Based on the ethnic, the majority of athletes belong to Malays $(43.72 \%)$ since they are the majority race in Malaysia. The second largest ethnic in Malaysia are Chinese. There are $31.60 \%$ athletes from Chinese ethnic. Indians are the lowest ethnic in Malaysia. There are $24.68 \%$ athletes from Indian ethnic.

The mean age for overall respondents was 21.77 years old. The age of male varied from 19 to 27 years, where the mean age was 22.17 years old. The age of females ranged from the minimum of 18 to the maximum of 26 years old. The mean age for female respondents was 21.14 years old.

\subsection{Cronbach Reliability Coefficients}

In this study, Cronbach alpha were found ranging from .77 to .85 . Coefficients of .70 and above were considered reliable, therefore included in the interpretation of the data (Table 2). 
Table 2. Cronbach Reliability Coefficients

\begin{tabular}{|c|c|}
\hline Motives of Taking Part in Sports & Cronbach's Alpha $(\mathrm{n}=231)$ \\
\hline Socialization & .8037 \\
High Status Career & .8381 \\
Green Space Area & .7627 \\
Music & .8571 \\
Body Shape & .8129 \\
Challenges & .7715 \\
\hline
\end{tabular}

\subsection{Motives of Malay Ethnic Taking Part in Sports}

The results showed that the motive of Malay ethnic respondents participated in sports were highest in Green Space Area $(\operatorname{mean}=3.71)$, followed by Body Shape (mean= $3.53)$, Socialization $(m e a n=3.21)$, Challenges $(\operatorname{mean}=2.71)$ and High status career (mean $=2.18$ ). The Malay respondents indicated music as the lowest motive (Table 3 ).

Table 3. Motives of Malay Ethnic Participation in Sports $(n=101)$

\begin{tabular}{cc}
\hline Motives & Mean \\
\hline Green Space Area & 3.71 \\
Body Shape & 3.53 \\
Socialization & 3.21 \\
Challenges & 2.71 \\
High Status Career & 2.18 \\
Music & 1.98 \\
\hline
\end{tabular}

\subsection{Motives of Chinese Ethnic Taking Part in Sports}

The results showed that the motive of Chinese ethnic respondents participating in sports were highest in Body Shape (mean=3.45), followed by High Status Career (mean= $3.15)$, Socialization $($ mean $=3.07)$, Music $(\operatorname{mean}=2.99)$ and Challenges $($ mean $=2.59)$. The Chinese respondents indicated Green Space Areas as the lowest motive (Table 4).

Table 4. Motives of Chinese Ethnic Participation in Sports $(\mathrm{n}=73)$

\begin{tabular}{cc}
\hline Motives & Mean \\
\hline Body Shape & 3.45 \\
High Status Career & 3.15 \\
Socialization & 3.07 \\
Music & 2.99 \\
Challenges & 2.59 \\
Green Space Area & 2.43 \\
\hline
\end{tabular}

\subsection{Motives of Indian Ethnic Taking Part in Sports}

The results showed that the motive of Indian ethnic respondents participating in sports were highest in Socialization $($ mean $=3.73)$, followed by Challenges (mean= 3.61), Green Space Area (mean=3.51), Music (mean=3.09) and Body Shape (mean=3.03). The respondents indicated
High Status Career as the lowest motive (Table 5).

Table 5. Motives of Indian Ethnic Participating in Sports ( $n=57)$

\begin{tabular}{cc}
\hline Motives & Mean \\
\hline Socialization & 3.73 \\
Challenges & 3.61 \\
Green Space Area & 3.51 \\
Music & 3.09 \\
Body Shape & 3.03 \\
High Status Career & 2.15 \\
\hline
\end{tabular}

\section{Discussion}

\subsection{Motives of Malay Ethnic Taking Part in Sports}

The results showed that the motive of Malay ethnic respondents participating in sports were highest in green space area. Therefore sports developers should focus on green space environment area surroundings to attract Malay ethnic customers. The most common place that resemble green space environment like natural or semi natural habitats, rivers, canals, parks, gardens, street trees, parks, golf courses, sports fields, mountain view, sounds of running water, grass, flowers, the scene of cool mountain water, the breath of fresh air, and so on. Green space environment has a positive impact on mental health (Tabbush \& O'Brien, 2003). Furthermore, green space environment has the tendency to reduce stress and anxiety (Vincent \& Yahaya, 2012).

\subsection{Motives of Chinese Ethnic Taking Part in Sports}

The results showed that the motive of Chinese ethnic respondents participated participating in sports were highest in body shape. Therefore sport developers should focus on body shape programmes, environment, techniques or environment to attract Chinese ethnic customers. Study done by (Ro \& Hyun, 2012) showed that body shape satisfaction was significantly higher in Chinese ethnic compared to Korean. In Malaysia, Chinese look much fitter in their body shape compared to other races. Body shape is the motive to take part in sports for physical reasons, notably health, weight, or keeping fit (Kilpatrick, Hebert \& Bartholomew, 2005; Wann, 1997). Taking part in sports for body shape are important to reduce the risk of coronary heart disease, cancers, obesity and many other health related problems (Adair, 2008; Allender, Cowburn \& Foster, 2006). Taking part in sports to keep the body shape look attractive enhances the fitness level, improves the immune system, mental health, maintaining healthy bones, reducing health problems and increases the effective functioning of the body organ.

\subsection{Motives of Indian Ethnic Taking Part in Sports}


The results showed that the motive of Indian ethnic respondents participating in sports were highest in socialization. Therefore sports developers should focus on socialization environment to attract Indian ethnic customers. Sport centers, where people easily can move around, cafeteria and chatting corner, may attract Indian customers. Socialization motive is an interest in people and the ways a person prefers to relate to other people (Wann, 1997). A study conducted by (Wang, Myers \& Yanes, 2010) and (Sabiston \& Crocker, 2008) found that the interaction among their colleagues encourages people to participate in sports. As social beings, humans have a desire to be with others and to function as members of groups. For many people, the social aspects of sports were important reasons for their participation. For the most part, one's motivation to take part in sports will derive from something relating to a social environment, like to enjoy camaraderie and to mix socially with others who enjoy the same activity (Funk, Mahony, \&Ridinger, 2002; Yan \&McCullagh, 2004). Social reasons for taking part in sports range from meeting new people to deal with loneliness and social isolation. Research of (Henderson \& Ainsworth, 2001) showed that social environment was the most important motives of African-American and American Indian women choosing to be active in sports.

\section{Conclusion and Recommendation}

This research showed that the motives of taking part in sports among different ethnic groups vary. A Malay ethnic group taking part in sports for green space environment, Chinese for body shape, while Indians for socialization environment.

Sports psychologists and developers of sport environment can use this research to develop appropriate environment for Malays, Chinese and Indians, to maintain their interest in sports. In addition, identifying the range of motives given by Malays, Chinese and Indians will help sports centers to provide adequate and variety of sports products, environment or programmes regarding their motives in sports. In particular, government officials, private sectors, sports psychologists and sports industries in Malaysia need to conduct sports centers, products or services to encourage different ethnics in Malaysia to take part in sports could use the findings of this research.

\section{REFERENCES}

[1] Adair, L. S. 2008. Child and adolescent obesity: Epidemiology and developmental perspectives. Physiology \& Behavior 94, 8-16.

[2] Allender, S., Cowburn, G. \& Foster, C. 2006. Understanding participation in sport and physical activity among children and adults: a review of qualitative studies. Health Educ. Res.
$21,826-835$.

[3] Bennett, R., Mousley, W., Kitchin, P. \& Ali-Choudhury, R. 2007. Motivations for participating in charity-affiliated sporting events. Journal of Customer Behaviour. 6(2), $155-178$.

[4] Brehm, B. A., 2004. Your role in the exercise adherence story. Successful fitness motivation strategies. Champaign, IL:Human Kinetics.

[5] Devine, R. \& Lepisto, L. 2005. Analysis of the Healthy Lifestyle Consumer, Journal of Consumer Marketing, 22 (5), 275-283.

[6] Funk, D., Mahony, D. \&Ridinger, L. 2002. Characterizing Consumer Motivation as Individual Difference Factors: Augmenting the Sport Interest Inventory (SII) to Explain Levels of Spectator Support, Sport Marketing Quarterly, Vol. 11 , No. 1, pp. 33-43.

[7] Gill, D.L., Gross, J.B., \& Huddleston, S. 1983. Participation motivation in youth sports. International Journal of Sport Psychology, 14, 1-14.

[8] Henderson, K., \& Ainsworth, B. 2001.Researching leisure and physical activity with women of color: Issues and emerging questions. Leisure Sciences, 23(1), 21-34.

[9] Kahn, J. S. 1998. Southeast Asian Identities: Culture and the Politics of Representation in Indonesia, Malaysian, Singapore and Thailand. Singapore: Institute of Southeast Asian Studies.

[10] Kilpatrick, M., Hebert, E., \& Bartholomew, J. 2005. College students' motivation for physical activity: Differentiating men's and women's motives for sport participation and exercise. J Am College Health, 54, 87-94.

[11] Lindner, K. \& Kerr, J. 2001. Predictability of Sport Participation Motivation from Metamotivational Dominances and Orientations. Personality and Individual Differences, Vol. 30(6), 759-773.

[12] Malaysia Demographics Profile 2012. (http://www.indexmu ndi.com/malaysia/demographics_profile.html).

[13] Ro, Y \& Hyun, W. 2012. Comparative study on body shape satisfaction and body weight control between Korean and Chinese female high school students. Nutr Res Pract, 6(4), 334-339.

[14] Sabiston \& Crocker. 2008. Exploring self-perceptions and social influences as correlates of adolescent leisure-time physical activity. Journal of Sport \& Exercise Psychology, 30 (1), 33-22.

[15] Sim Poh Chuen. 1994. Motif penglibatanatlitUniversiti Putra Malaysia dalamkegiatansukan. Unpublished degree's thesis.Universiti Putra Malaysia, Serdang, Malaysia.

[16] Tabbush, P. \& O'Brien, L. 2003.Health and wellbeing: trees, woodlands and natural spaces: Forestry Commission.

[17] Vincent, P \& Yahaya, M. 2012.Anxiety and Imagery of Green Space among Athletes.British Journal of Arts and Social Sciences, 4(1), 67-72.

[18] Wang, L., Myers, D., \&Yanes, M. 2010. Creating student-centered learning experience through the assistance of high-end technology in physical education. Journal of 
Instructional Psychology, 37(4), 352-356.

[19] Wann, D.L. 1997. Sport Psychology. Upper Saddle River, New Jersey: Prentice-Hall.

[20] White, S. A., \&Duda, L. D. 1994. The relationship of gender, level of sport involvement, and participation motivation to task and ego orientation. International Journal of Sport Psychology, 25(1), 4-18.

[21] Yan, J. H., \&McCullagh, P. 2004.Cultural influence on youth's motivation of participation in physical activity.Journal of sport behavior, 27(4), 378-390. 